\title{
Client engagement and building design: the view from actor network theory
}

Article

Accepted Version

Kurokawa, M., Schweber, L. and Hughes, W. (2017) Client engagement and building design: the view from actor network theory. Building Research and Information, 45 (8). pp. 910925. ISSN 1466-4321 doi:

https://doi.org/10.1080/09613218.2016.1230692 Available at https://centaur.reading.ac.uk/66681/

It is advisable to refer to the publisher's version if you intend to cite from the work. See Guidance on citing.

To link to this article DOI: http://dx.doi.org/10.1080/09613218.2016.1230692

Publisher: Taylor \& Francis

All outputs in CentAUR are protected by Intellectual Property Rights law, including copyright law. Copyright and IPR is retained by the creators or other copyright holders. Terms and conditions for use of this material are defined in the End User Agreement.

\section{www.reading.ac.uk/centaur}

\section{CentAUR}

Central Archive at the University of Reading 
Reading's research outputs online 


\title{
Client engagement and building design: the view from actor network theory
}

\begin{abstract}
The accommodation of client expectations in a construction project is challenging. This is, in part, because a client is rarely a single individual and their expectations are rarely static. This paper uses the actor network theory (ANT) concepts of problematization, enrolment and durability to explore client engagement. The contribution of ANT lies in its (ontological) model of distributed agency, fluid heterogeneous networks and associated effects. A pilot study of a single building project provides an opportunity to theorize the different ways that clients engage in the development of a building.. Client engagement differs with the direct versus mediated presence of different client actors, with the devices used to mediate negotiations and with the relative materiality of the network. The findings move the discussion of client engagement beyond the usual calls for better integration to an awareness of the mechanisms by which clients engage. Some decisions are fixed in material objects, while others remain open to ongoing negotiation. There is a need for explicit and continuous interaction and better awareness of when and how decisions are fixed. This would help all participants to deal with the complex and dynamic landscape of people, organizations and interests usually labelled as 'client'.
\end{abstract}

Keywords: actor network theory, client goals, design decisions, intermediaries.

\section{Introduction}

The construction sector seems to be beset with client dissatisfaction (Liu and Walker 1998; Leung, Ng and Chung, 2004). The topic is a recurring theme in policy reports (see, for example, Murray and Langford's (2003) overview of UK construction policy reports over more than 50 years) and is frequently connected to calls for performance improvement. While there is certainly a logical link between performance and satisfaction (and often a contractual link in that suppliers' final payment is usually linked to conformance with a 
specification), this dominant discourse obscures the complex and changing nature of client goals. Much of the policy discourse and associated research treats 'clients' as external, single actors with fixed goals. 'Satisfaction' is seen as a fit between initially-specified goals and physical characteristics of the building delivered. However, most practitioners, and a growing number of researchers, recognize that things are more complicated on the ground. Client organizations generally involve multiple actors, with very different expectations. Individual client expectations change; satisfaction ebbs and flows.

This paper contributes to the growing recognition of these complexities by exploring the involvement of multiple client actors in the negotiations around a number of design issues which arose in the course of a single project. By focusing on the set of actors involved in the negotiation, the analysis shifts the focus from clients as a source of external input and postconstruction evaluation, to clients as one of a number of groups shaping a succession of decisions. This perspective, in turn, allows for exploration of different ways in which clients engage.

The review of literature on client engagement documents a growing recognition of the complex, multiple and dynamic character of clients, as well as limitations to that view and, in particular, the persistent tendency to treat clients as radically distinct from the project team. A contribution of this paper is to explore what client engagement looks like when that distinction is removed. The point is not to discount the client's very different contractual and political status in a project, but to treat those differences as an empirical topic rather than as a set of a priori assumptions.

The empirical research was produced through the lens of actor network theory (ANT). The approach is increasingly being mobilized within construction management research.

Whereas most of this work uses ANT to explore the contribution of non-human actors to the construction process, this study focuses on a related aspect of ANT; namely its (ontological) model of dynamic networks and effects. A key feature of this approach is the concept of distributed agency. Viewed from this perspective, the study of client engagement becomes a 
study of the multiplicity of different local (dynamic, heterogeneous) networks in which clients are engaged, and their effect on clients and on the building.

The focus on one particular actor group necessarily breaks with a strict ANT analysis. As such, the research has been organized in two distinct phases: an ANT analysis of 'controversial' design decisions and a second, separate reflection on the picture of client engagement that the ANT analysis suggests. This unconventional use of ANT necessarily limits the detail offered in the reporting of the ANT analysis, but conversely provides a basis to directly engage with the broader construction research literature and its claims concerning client needs. The research reported here is exploratory. It is based on one project and uses retrospective accounts by key actors to document negotiations around three issues in the course of the project. The case involves negotiations around the development of a new academic campus building; while the issues may be specific to this building, the modes of client engagement are not. The three issues are negotiations around the physical location of the building, the layout of different rooms and TV studio acoustics. As indicated above, an ANT analysis of the negotiations provides the basis for reflection on modes of client engagement. Client engagement is seen to differ with the direct versus mediated presence of different client actors in specific design decisions (where decisions are treated as a process), with the devices used to mediate negotiations and with the relative materiality of the network. The conclusions include reflections on the relevance of this analysis for the current literature as well as practical recommendations.

\section{The client role in the construction sector}

Client engagement has long been a topic of interest for construction research. For example, Cherns and Bryant (1984) discussed client choice and organizational complexity in a small sample of diverse projects. Within this literature, clients have been depicted in a variety of ways. 


\section{The external, static client}

Studies of client engagement often limit their analysis to activities at the beginning a project, effectively depicting the client as external to the processes of design and construction. An example of front-end studies can be seen in research on client requirements. This work seeks to objectively identify precise client requirements in order to apply operational research techniques to the choice of contractors (e.g. Chinyio et al. 1998). In contrast, Bresnen and Marshall (2000) used exploratory case studies to analyse client-contractor collaboration as a management issue. Their focus was the ongoing relationship at a business-to-business level. They explored how the management of this relationship influenced choices around contracts. Hedgren and Stehn (2014) analysed in detail the organizational processes of decisionmaking in a client organization with a view to dealing with the complexities of setting up a project with an innovative technology. These are just a few examples of the methodologically and theoretically varied literature which treats the client as (an external) project initiator.

Another common feature of much of the literature on clients is a focus on the supply side of the construction process, rather than the demand side. Contractors, consultants, component manufacturers and materials suppliers tend to be depicted as focusing on the efficiency of their delivery processes. For example, Yeung et al. (2007) developed a performance index for the relationship between clients and their projects. In that study all actors were treated as equally significant and as individual entities. This tendency to deal with complexities of the issues as if there were a single, best solution awaiting discovery is typical of a lot of research in this area and rather unhelpful when it comes to understanding the way that people in different roles interact with each other. Researchers interested in the construction process often focus on construction as a single, universal engineering process that is in need of improvement, as if there were no differences between what various parties seek to achieve from the economic activity associated with the construction industry. 
More broadly, the problem with a focus on the supply side of the construction process is that suppliers need to figure out what the market demand is and then respond to that efficiently and consistently. The last thing they want is demand that is continually changing. Rather than seeking to understand why construction clients may be inconsistent and uncertain in what they want from the industry, commentators of many kinds have lambasted the construction sector for producing buildings late, over budget and of poor quality. There is a somewhat regular litany of this kind of criticism that has resurfaced repeatedly in a series of reports in the UK, for example, such as Banwell (1964), Latham (1994) and Egan (1998).

Gann and Salter (2000), in their seminal paper on innovation in construction firms, continue to see the client as an initiator of a project and somewhat external to the process. However, one of their conclusions touches on the need to re-conceptualize construction clients: "Project-based methods of production create a need to understand knowledge flows in client and supplier relationships that extend beyond the traditional economic notion of 'an industry'" (p. 970). This paper contributes to that task by situating the client in the dynamic interaction around design decisions.

\section{The changing, engaged client}

Boyd and Chinyio (2006) produced what appears to be a unique text-book in the construction literature, where the entire book focuses on the role of the client in the process. Interestingly, their start point is that "buildings are about changing and developing the client" (p. xi). This is in sharp contrast to literature that focuses on clients as external to the process, whether as mere initiators or slightly more engaged in some kind of approval role (e.g. Shen et al., 2004; Bowen et al., 1999).

Morris (1994) long ago argued that project management is more than simply realizing a specification to time, cost and quality. For him, the distinction between management of projects and project management was that the former called for a strategic approach involving the client at every step and the latter for a toolbox of techniques for delivering the 
project according to agreed targets. Winch (2012, p.13) eloquently connects the task of managing construction projects to various theoretical perspectives. Of most interest for this paper is the idea that "projects are temporary organizations consisting of a coalition of firms chartered by the client" (p. 13). Drawing on Engwall (2003) and Giddens (1984), he also states that "projects are embedded in contexts that are both organizational and institutional, simultaneously shaping and being shaped by these contexts" (p. 13). This position forms a strong basis for critiquing a vast swathe of literature on construction clients and project management. The work on efficient project delivery based on handover and sign-off of information treats the client as a source of information in relation to requirements and the source of payment for work done. But this misrepresents the problem so clearly identified by Winch, among others.

\section{Client needs}

There is a preoccupation in the project management literature with the idea that client's needs revolve around time, cost and quality. This is a central theme in many reports, books and papers. But it tends to represent the supply side's interests in that the idea is to get a client to sign-off agreed targets for these performance criteria early in the process so that the project management team can then manage the project according to these pre-agreed requirements.

A different approach to this problem can be found in Winch's (1988) study of innovation which, he argued, depended on ongoing negotiations between the large numbers of participants in the construction process. Although Winch did not mention clients, his call for case studies of the trajectory of specific innovations identifying how ideas come about and how they are managed into good "currency" is important. An intermediate step is to develop techniques for identifying how the actors generally bracketed as a unitary client negotiate decision-making processes around the specification of construction work. This paper illustrates the application of ANT to that task. 


\section{ANT and the study of client engagement}

ANT developed from a concern by sociologists of science to move beyond the radical distinction between nature and society to a more realistic approach which embraces the heterogeneous character of all human activity. At the core of the approach is a postmodern ontology which focuses on the production of effects by heterogeneous actor networks, combining human and non-human 'actants', as well as a variety of devices which link them together, often across time and space (Law, 1992; Latour, 2005). An important implication for this paper is the shift in the location of agency from individual (human) actors to the network as a whole. This analytic move is captured by the use of the term 'actant' to refer to those actors (human and non-human) that make a difference (Latour, 2005, p.71). A key point is that individual actors never make a difference all by themselves. Instead agency is distributed across the network.

A core methodological principle of this approach is symmetry. This is the methodological prescription to treat all actants the same. The principle initially arose from a commitment to analyse all scientific claims in the same way, independent of whether they were currently deemed 'true' or 'false' by the scientific community (Bloor, 1976). Instead of assuming that 'true' scientific claims could be explained by nature and 'false' claims were the result of ideology or self-interest (society), ANT scholars set out to examine how claims came to be elaborated and recognized (Woolgar and Latour, 1986; Latour, 1988, Callon, 1986a,b). A shift from the study of scientific claims to the study of technology led to a parallel rejection of the distinction between the technical and the social (Latour, 2005). It is this methodological principle of symmetry combined with the notion of distributed agency, which leads ANT scholars to treat human and non-human actors in the same way. In reflecting on this point, it is helpful to keep in mind the scope of ANT's own claims. As Law explains, "to say that there is no fundamental difference between people and objects is an analytical stance, not an ethical position" (Law, 1992, p 383). 
The use of ANT to study projects is well developed. Several classic ANT studies focus on commercial projects (e.g. Callon, 1986a; Law and Callon, 1992; Latour 1996). In each of these cases, the effect of the project is not only the outcome - be it the failure of a project to construct fighter jets (Law and Callon, 1992) or the failure to market an electric car (Callon, 1986a) - but also the transformation of the wide range of different actors, human and nonhuman, engaged in the process. As an aside, it is interesting to note the number of ANT studies which explore 'failure'. This reflects both a strength of the method and an application of the principle of symmetry, which refuses to privilege either success or failure.

In the case of client engagement, ANT allows for a study of the presence (and absence) of clients in ongoing negotiations around emergent issues. The approach draws attention to the way that engagement in a construction process potentially transforms the client and, by association, their goals. While the idea that client goals change is not new (see above), the depiction of client goals as the effect of their participation in dynamic, heterogeneous network is. The approach was explored by Tryggestad et al. (2010) in their study of the Turning Torso, an iconic building in Denmark. Whereas their paper focused on the project level, this research explores specific design decisions in an attempt to theorize variations in client engagement over the course of a project.

Within construction research, ANT studies tend to adopt a 'light touch', mobilizing one or more key concepts. In terms of research object, construction research has tended to focus on different aspects of specific building projects. For example, Trygstaad et al (2010) privileged the role of material objects to explore the ongoing transformation of project goals. In contrast, Harty drew on ANT's attention to the openness and fluidity of network boundaries to explore the range of actors and effects associated with the uptake of $3 D$ CAD $(2005,2008)$. Finally, Lingard et al. (2012), used the concepts of multiple interactions and heterogeneous networks to explore the evolution of specific design decisions ("embedded units"). The study of clients developed in this paper is closest to Lingard et al's (2012) use of ANT in its exploration of distributed agency in dynamic, heterogeneous networks. 
In each of these studies, a broader substantive or theoretical issue provided the focus for the inquiry and justified the analytic frame. In Harty $(2005,2008)$, the broader issue was innovation, for Lingard et al (2012) it was occupational health and safety (OHS) and in Tryggestad et al (2010) it was project goals. Other construction topics examined from an ANT perspective include: Alderman and Ivory (2011) on the role of the project manager and Sage et al. (2014) on the way that animals shape the specification of project boundaries. What all of these studies share is a focus on the multiplicity and diversity of actors (including nonhuman actors) who make a difference for the problem at hand, a study of the processes of association and dis-association (rather than the actors themselves) and an emphasis on the contingency and uncertainty of these processes.

The implications of adopting ANT to study client engagement are multiple. Instead of assuming that clients are, by their nature, different from other stakeholders, the study treats them symmetrically. Instead of looking for who made a decision about a specific design feature, the research explores the set of human and non-human actors engaged around the ongoing specification of the issue. Following ANT, it treats the fixing of a particular design feature as the effect of a network, containing a range of actors, human and non-human. This analysis, in turn, provides a basis to re-visit the issue of client engagement and its different modalities from a very different basis. The analysis of design decisions builds on three ANT concepts: problematization, enrolment and durability.

The terms 'problematization' and 'enrolment' are often explained with reference to Callon's study of research into the cultivation of scallops in St. Bruic Bay (1986b). Problematization focuses on a single actor, or actor group, and refers to their specification of a project and of the associated set of human and non-human actors whose support is essential for its realization. For example, the French scientists in Callon's study had an elaborate problematization which ascribed a particular role for the fishermen and the scallops as well as for their colleagues and instruments. While the term 'problematization' might seem to imply a degree of individual agency (every problematization has an author), 
implementation depends on a process of persuasion, whereby the author(s) convince a myriad of other actors to adopt and support their vision (enrolment). Uncertainty flows from the possibility that those others may not follow. Complexity stems from the multiplicity of different problematizations which different actors bring to a negotiation. As this discussion indicates, the difference between the more conventional notion of 'interest' or 'goal' and 'problematization' is that the latter involves a vision not just for a preferred outcome, but also for the reconfiguration of actors and objects needed to realize it.

In Callon's (1986b) study, engagement of other actors in a particular problematization is broken up into three stages (interessement, enrolment and mobilization). Interessement refers to the initial engagement of other actors with a problematization, while enrolment refers to their acceptance of the proposition and mobilization refers to the ability of actors to deliver on their commitment to a particular network and effect, once enrolled, by bringing others (who they purport to represent) on board. While this distinction between enrolment and mobilization is useful, it is dependant on a level of detail that the data collected for this study did not afford.

The interest of problematization for this paper is that it is a dynamic (never-ending) process, in which both the definition of the project and the role (and identities) of the actors involved are continually shifting. As such, the concept provides a way to move beyond the fixing of client preferences to an initial point in a building project. It draws attention to client involvement in ongoing negotiations over what design features to incorporate into a building and why. Different problematizations are seen to be associated with different visions for the building, its use and the relevant stakeholders. Enrolment, in this context, draws attention to the processes by which actors' goals and by extension, identities, are transformed in the course of a project. Finally the ANT ontology suggests that client preferences and influence will vary with the type of network in which they are engaged and that different client actors may support different problematizations. The third concept, durability, has been introduced to explore variations in the way in which decisions 
(networks and their effects) are secured in the course of a project and their implications for client engagement.

The concept of durability refers to the temporary fixing of an actor network and the effect which it produces. This concept provides one way to think about the ephemeral search for consensus amongst project team members and the challenges of communication and coordination. One of the many contributions and specificities of an ANT approach is the attention it draws to the role of material objects in the fixing of decisions. In making this point, it is important not to confuse the concept of non-human actors with that of devices which serve to mediate and potentially fix decisions. The first refers to objects that actively participate in the constitution and development of issues, in this case, a design decision. The latter refers to objects which, while they do not actively participate in the negotiations (they do not make a difference), serve to facilitate it. For readers familiar with ANT, the distinction maps onto the contrast between 'mediators' and 'intermediaries' (Latour, 2005).

Within ANT, the concept of 'device' is curiously under-theorized. Thus, while many ANT scholars include 'devices' in the list of types of items from which networks are assembled (e.g. Law 1992, p. 379; Latour, 2005, p.76), they do not discuss how they function or their relation to human and non-human actors. Artifacts which may, in certain circumstances, function as devices include texts, reports, accounts, and tracers (Latour 2005, p.127). Within the literature on the built environment, Rydin (2013) has used ANT's interest in intermediaries to explore the role of planning documents and energy models in stabilizing networks around low carbon commercial developments. Similarly, Lingard follows the transformation of plant and equipment requirements from a more passive role as intermediaries to a more active role as mediators. As this discuss indicates, the question of whether material objects are treated as active or passive is an empirical problem, which varies with the research question, research object and moment in which the actor network is analysed. 
For ANT scholars, devices are of particular interest for the way they facilitate long-distance and long-term engagement (Law 1986). They also introduce durability into networks. As Law explains "when we start to perform relations - and in particular when we embody them in inanimate materials such as texts and buildings - they may last longer" (1992 p. 6). The implication is that the more material the network, the more difficult it might be to unravel. From the perspective of clients, this discussion suggests that client engagement may vary, depending on the devices by which they are linked into a particular network and the materiality of the network as a whole. This suggestion informs the reflection on modes of client engagement towards the end of this paper.

\section{Methods}

To explore client engagement, the research was divided into two distinct phases. The first involved an ANT study of three sets of negotiations that arose during the design and construction of a single project; the second involved the use of those three ANT analyses to reflect on modes of client engagement. The study of client engagement discussed herein focused on a single building project, that was used for the selection of three design issues, each of which involved an embedded network.

The research began from an interest in client engagement and the search for a building project. The only criterion was that it should involve multiple client actors. The selected building was designed to house facilities for the university's School of Film and Drama (SFD) and, as such, required the construction of special facilities, including theatre, film and TV production spaces. The client involved multiple university stakeholders, including, among others, individuals from the Office of the Vice Chancellor, Estates Management, the SFD and future users. A project feasibility study was conducted in 2007 and construction was completed in 2011. To maintain some degree of confidentiality, the names of the university, the building project and all participants have been changed for this study. This project has been subject to ethical review, according to the procedures specified by the 
University Research Ethics Committee, and has been given a favourable ethical opinion for conduct. Once the building project had been selected, pilot interviews with various client actors and project team members were conducted to identify issues that had been the focus of explicit differences and negotiations. ANT analyses often focus on controversies on the grounds that it is these occasions which offer researchers a window into negotiations surrounding seemingly rational or fixed outcomes. While negotiations are often experienced by the actors as involving a single issue, analysis usually reveals shifts in focus, producing a succession of loosely related issues. To the extent that issues were discussed in a contiguous fashion with significant overlap in actors (human and non-human), they were deemed to belong to the same negotiation. By the end of the first phase, three (sets of) issues were identified for further analysis. These included (1) the location of the building, (2) the floor plan of the building, and (3) the acoustics of the TV studio.

In an oft repeated mantra, Latour explained ANT's method as one of 'following the actors' (Latour, 1987). The precept reflects the principled refusal to make any a priori assumptions about the actors involved, be they human or non human. Real time ANT studies rely heavily on ethnography, while historical studies necessarily scour documents and archival material to reconstruct the shifting networks around a particular issue or outcome. The choice of a project which had only recently been completed placed this project somewhere between the two scenarios and supported the use of documents and interviews to reconstruct the shifting networks that shaped the ongoing negotiation around these three sets of issues. The timing of the interviews, well after the completion of the project, had both advantages and disadvantages. On the one hand, it supported relative consensus over the identification of issues which had been subject to ongoing negotiation; on the other hand, it limited the amount of detail which could be obtained concerning processes of enrolment (thus the focus on enrolment, rather than interessement, enrolment and mobilization)..

In collecting data, Latour's precept of 'follow the actors' was loosely followed. Every time an interviewee mentioned another actor or device it was followed up, except for a few 
instances in which it was deemed out of scope. In total 13 human actors were interviewed (see Table1). Interviews focused on the individuals' involvement in the building project and their perceptions of the project as a whole as well as of particular issues. In each interview actors were asked to describe the issues involved and how they were decided. General statements were queried with requests for specific examples and specific terms were probed. In the course of the interviews, information gleaned from the minutes of meetings and other documents were also introduced to elicit more elaborate or even alternate, accounts of what happened. If the aim of the study had been to document interviewees' recollections, this type of intervention could have been viewed as problematic. Given that ANT does not privilege one type of source or account as more credible (or, in positivist vocabulary 'objective), the technique added to the richness of the data. Documents consulted included: architectural floor plans, progress reports and meeting minutes.. In addition, progress reports and emails were used to analyse project participants' interests at different moments . All data, including interviews and documents, were treated as equally valid perspectives into the course of the negotiation. <place Table 1 near here>

Data was analysed through a number of iterations. Initial coding focused on the identification of negotiations. This was followed by continued data collection and a second iteration in which data was coded for problematizations and enrolments. A subsequent interest in devices and durability led to a third, more selective round of analysis.

Throughout the coding process, shifting network configurations and the interconnections of issues were analysed.

In a subsequent, distinct phase, the narratives were re-examined for modes of client engagement. While the practice of stepping back from an ANT analysis to focus on a particular actor or set of actors is not usual in ANT, theorization around concepts is. As with other forms of interpretivist analysis, generalization in ANT focuses not on the representativeness of the cases or the likelihood of precisely the same outcome being recurring, but rather on the identification of processes and mechanisms (Schweber, 2015). 
This type of generalization is clearly evidenced in Harty's $(2005,2008)$ discussions of the boundedness of innovations (as discussed in detail by Schweber, 2016). In this paper, the analytic focus is driven by an interest in modes of client engagement.

Like every paper, this one has limitations. In terms of data, reliance on after-the-fact accounts necessarily limited the analysis and in particular precluded a detailed account of mobilization. If the aim of the paper had been to demonstrate the agency of non-human actors, then this might have been a serious problem. Given the focus on problematizations, enrolment and durability and the aim of the analysis to use these concepts to explore client engagement, it was not deemed significant. Looking forward, ANT analyses of detailed design and project team dynamics would benefit from ethnographic and real time longitudinal analysis.

\section{Building location}

The first issue, building location, involved a number of actors from the university, the master plan architect, members of the public and visitors to the university. Negotiations around the issue can be divided into two phases. These include an initial phase involving the architect, heads of a number of Schools from the Faculty of Arts and Humanities and a representative of Estates Management, and a second phase involving these actors, plus: students, staff, the public and the Office of the Vice Chancellor. It is helpful to note that, with the exception of the architect, all of the actors in this network were 'clients' in the conventional sense of the term. The vignette illustrates the way that negotiations over specific design decisions involve different depictions of the client actors and their interests (competing problematizations), the use of devices to capture and communicate those depictions and the role of human and non-human actors in challenging them.

\section{The university as defender of student life versus community outreach}

Negotiations surrounding the location of the building began when a representative from the university Estates Department identified two potential building sites on either side of the 
Purbeck building. The Purbeck building was in the same Faculty as the SFD and both proposals fitted with Estates Management's commitment to spatial integration of Faculties. Negotiations surrounding the location of the new SFD building were part of a broader conversation about the physical place of the Faculty on campus. While the coupling of the two buildings was uncontroversial, the question of whether it should be to the eEast or the west was not.

In the discussion which ensued, two distinct problematizations were put forward. The architect favoured a position to the east of the Purbeck building on a green open space in the centre of the campus. The proposal was presented in the name of students and staff, who, the architect argued, would benefit from the vibrant civic atmosphere which the introduction of a theatre in the centre of the campus would create. In contrast, the Heads of School put forward a problematization in the name of the visiting public. A Film and Drama building with its multiple theatres and performance spaces on the Western side of the Purbeck building, they argued, would be more visible and provide better access to the public. In these two problematizations, actors from the University were positioned in two different ways. In the first, they were defined as defenders of students and staff; in the second they were contributors to the cultural life of the local community.

In considering this negotiation, it is important to note that both the student body and the broader public were not party to the negotiation, either in the form of direct participation or through a formal representative. Instead they entered indirectly, through the architect's and Heads' rationales for their preferred location. Similarly, the plans depicting the two options were equally easy to change (fluid, or not durable).

To move the negotiation forward, the architect wrote a report defending his proposal in the name of the visiting public (the group in whose name the Heads of Schools had previously spoken). As he noted in his report:

... [the SFD's] location will, therefore, be influenced by whether the University wishes to encourage visitors into the heart of the campus, or whether it would prefer 
to maintain a degree of separation by locating it at the periphery of the built core.

(Master Plan Architect Report, August 2008).

By reframing his proposal in the name of this second constituency, the architect effectively relieved the representative from Estates Management of the need to privilege one constituency over another. Based on this more inclusive formulation, the Heads of Schools changed their preference to the eastern location and the Office of the Vice Chancellor approved it.

\section{Students, staff and the public as defenders of green space}

In the second phase of this negotiation, attempts were made to actively enrol both the student body and the broader public. This was prompted by the local planning authority and its requirement for a public consultation. The requirement and the way it was met transformed the students and the public from two actors into a single actor and from concepts in someone else's problematization into a set of comments in a box. This materialisation of the students and the public, in turn, gave them an active voice. Instead of supporting the architect's problematization, they resisted.

The public consultation was held for six weeks in a building on the University campus. It involved a display of the campus masterplan, with an indication of the position of a number of planned buildings, including the Film and Drama building. University students, staff and local residents were invited to review the plan and to provide written comments in a small box. The plan itself communicated a much reduced version of the proposed location. It positioned the SFD building in the middle of an open green space; but it did not communicate either of the two problematizations discussed above. For example, the presentation did not state that the SFD would house the public theatre or shared teaching spaces. In ANT terms, the campus map on the exhibition board served as a mediator or actant which eastoffered an alternate problematization to that of the architect or the Heads of School By leaving out the rationale, the campus map drew attention to the position of the proposed building on an existing green space. 
Whether a more elaborate problematization would have persuaded the public to support the location or not is impossible to ascertain. What is known is that, while some comments either supported the Eastern location or asked for more information, the majority rejected it. Comments included statements such as "will have serious negative impacts on our ability to recruit students if green space is removed" (University employee and resident); “very obtrusive location - cutting in half one of the few well-planned open spaces on campus" (University employee); and "should not be built here under any circumstances; would make university look cramped and darker" (University student).

In the end, this third problematization, which positioned the University as a defender of the green space was strong enough to win the day. While the public failed to enrol either the architect or the Dean of the Faculty, who continued to support the Eastern location on the grounds that it contributed to academic integration, they did succeed in persuading the Office of the Vice Chancellor. As the Deputy Vice Chancellor explained:

I would have ... probably have favoured putting something slightly more permanent ... a slightly more visible building ... the difficulty with (the east location is) ... it turns an open space into some sort of narrow space, which ... might have proved unpopular with colleagues (Deputy Vice Chancellor interview, April 2013).

Following the consultation, a third option of locating the building in an existing car park was introduced by the master plan architect and eventually chosen over the previouslyselected east option.

\section{Space allocation}

The second negotiation to be examined concerned the area, location and adjacency of various functional spaces within the building footprint. Actors included a succession of floor plans, the architect, project manager and a newly appointed SFD representative, who had served as Head of School, but stepped down to oversee this project. The vignette illustrates the multiplicity of stakeholders that client actors take into account and the role of non- 
human actors and the negotiation process in the privileging of one over the other, often without the client fully realizing that that is what has happened.

The negotiation began in 2007 when the architect and SFD representative discussed functional requirements for the building. The SFD representative's wish list included five large performance spaces (three theatres, a screening space and TV studio) and a large storage space to accommodate props, ladders and rostra. The architect was concerned that not all of these could be accommodated. The architect produced an initial rough drawing, which was amended during discussions over the budget. This vignette focuses on the subsequent discussion.

A striking feature of this negotiation involved the tensions between different problematizations put forward by the SFD representative in the course of the negotiations. Far from evidence of enrolment or, in lay terms, a change of mind, this tension reflects the multiple constituencies which a single actor may purport to represent at the same time. The negotiation can be narrated in two concurrent phases: an initial discussion of the location and height of Theatre 1 and a second negotiation around the location and size of the storage room.

\section{So what if the performers are too hot?}

In the first phase, negotiations circled around the height (one storey or two) and location (ground floor or first floor) of Theatre 1. In the initial rough plan, the architect depicted Theatre 1 as a single-storey room on the ground floor. Following the budget decision and the shrinking of the building footprint, he moved it to the first floor; this was in keeping with his vision for the building which included large open spaces on the ground floor. The SFD representative, in contrast, wanted Theatre 1 to extend across two storeys. A lower theatre height, she argued, would reduce the lighting aesthetics. In addition, heat from lower ceiling lights would heat the stage and be uncomfortable for performers. In this initial discussion of the vignette, the architect enrolled the already fixed budget and newly truncated floor plan 
in support of his commitment to open spaces while the SFD positioned herself as spokesperson for (different) aesthetics and for the performers.

In the course of the discussion, the SFD realized that, if she compromised on this issue, she might get her way on the spatially-related issue of the storage room (see below) and she acquiesced. As she explained: “... it is very low for a theatre and, therefore, in some ways, not ideal. On the other hand, I thought we would lose that space" (SFD representative). Curiously, once this decision was made, both the aesthetics and the thermal comfort of the performers dropped off the SFD representative's agenda; from then on, her engagement focused on the location of storage space relative to Theatres 1, 2 and 3.

\section{Defending the production crew}

From the beginning of the project, the SFD representative was committed to maximizing storage space, in close proximity to the theatres. This concern was presented in the name of the performance crew who would have to carry heavy props and equipment back and forth. The new version introduced a large storage space on the ground floor between Theatre 2 and 3. This proposal addressed the SFD representative's concerns for the performance crew by reducing the distance from the storage room to Theatres 2 and 3 . The storage space was also large enough to be used for other purposes, such as conferences, theatre performances and filming.

After a period of protracted discussion, the SFD representative accepted the new proposal. This positioned her as a defender of the backstage crew, but only if they were working with Theatres 2 and 3 (Theatre 1 remained a floor above the storage, making changes to the stage cumbersome), defender of the department (with the flexibility to put on multiple performances and hold conferences), but a weaker defender of the performers and their need for comfortable, well-ventilated performance spaces. In considering this vignette, it should be noted that both performers and the performance crew were students. 
The privileging of the storage space, out of all of the different considerations which the SFD representative had raised, can partly be understood as a result of the process by which she was enrolled. In an attempt to communicate to the SFD representative the limitations of the building footprint, to figure out which of the SFD representative's multiple concerns were non-negotiable and to enrol her in an eventual design, the architect used space cards on an outline of the building footprint. Negotiations were conducted around and through the movement of cards across the plan. This device effectively focused attention on the spatial layout, at the expense of the thermal comfort of the performers. Had someone asked the SFD representative in the opening of the negotiations to prioritize the different constituencies which she represented, it is likely that she would not have listed the student stage crew over the student performers. However, this is what happened.

From an ANT perspective, this vignette illustrates a number of points, including the ability of devices such as the floor plan and space cards to 'make a difference', the multiplicity of potentially conflicting considerations, which a single actor juggles in the course of a negotiation (often without even realizing it) and the ability of one actor to challenge another's problematization by disassociating a particular commitment from the representatives with which it was initially associated.

\section{Studio acoustics}

The third vignette traces the negotiations over how to sound proof the TV studio. Key actors included the acoustician, the project manager and the architectural technician. The vignette illustrates the way in which devices both introduce and black-box the effects of negotiations which were (temporarily) stabilized in the past and the use of those devices in the longdistance participation of clients in negotiations. The analysis also highlights the way in which the overlay of different devices contributes to the durability of certain decisions.

\section{Sticking to the plan versus perfect recordings}


The account begins with a set of decisions concerning noise rating (NR) levels and the roof floor plan which had been stabilized prior to the negotiation. The SFD representative went into the project with a mandate to protect future occupants of the building from noise, in general and in the TV studio in particular. In the previous building, microphones had routinely captured ambient noise, including the sound of rain on the building's roof. As representative for the School, it was her job to ensure that the experience was not repeated. To address this concern, the acoustician proposed an NR level of 20 for the TV studio; this was higher than usual and difficult to achieve. In the specification of NR levels, the SFD representative enrolled the acoustician in her goals for the TV studio and other rooms. However, in doing so, she was also enrolled in the acoustician's ambitious targets and exclusive focus on sound, potentially at the expense of anything else.

In a second, prior set of negotiations, the SFD had also overruled an initial proposal for a more energy-efficient ventilation system in favour of a more standard system. This was significant, because the air-handling units (AHUs) in the standard system were significantly larger, leaving little to no flexibility in the roof floor plan, which included offices and spaces for the AHUs, chiller and boiler room. At the time, she did not realize the implications that this decision would have on the acoustic insulation of the TV studio.

At the start of the negotiation, the boiler room was situated directly above the TV studio. According to the plan, four drainage pipes would penetrate the floor system below the boiler room, potentially bridging the floor system and, most likely, transmitting sound from the boiler room to the studio below. Being expensive, the acoustician had not been involved in the prior development of the roof floor plan. When he eventually saw it, he voiced his concerns in a written report. The report explained that this arrangement risked the possibility of a flanking path (which refers to the effect of sound moving from one space to another through direct and indirect pathways). The report called on the project team to locate the boiler room 'somewhere else'. From an ANT perspective, the absence of an 
alternative problematization did not strengthen the argument. The negotiation thus involved a contest between two devices: the floor plan and the report.

\section{A show of force}

On receiving the acoustician's report, the project team responded with a flat 'no'. The proposed movement of the boiler room 'somewhere else', they argued was impossible. At this point in the negotiation, the different parties were at an impasse. The architectural technician was committed to the problematization contained in the plan; the acoustician was committed to the alternative, somewhat vague, problematization proposed in the report. Both commitments had been fixed in prior negotiations and rendered durable in the form of a number of interlocking documents. For the architectural technician, these included the above-mentioned floor plan, the services engineers' area schedule, the architects' plans and the services engineers' drawings. They also involved the interdependence of the different spaces within the plan and the size of the AHUs. For the acoustician, negotiations with the SFD representative over the problem of noise had been fixed in an NR rating of 20. This was supported by his report.

In the end, the architectural technician's plan proved to be the stronger of the two and the acoustician was forced to back down. The acoustician accepted the boiler room location with the drainage pipes penetrating the floor system above the TV studio. To address the problem of noise, he proposed treating the drainage pipes and brackets with a mineral fibre wrapping over and cladding with a sound barrier mat to make them acoustically-lagged (Acoustician report, October 2009). This move allowed him to enrol in the plan's positioning of the boiler room above the TV studio, without completely abandoning his commitment to acoustic quality. He explained that, while the proposal constituted a high level of treatment, the risk of sound leakage remained.

An interesting feature of this analysis is the intransigence that the different parties brought to the negotiation as well as the relatively limited number of problematizations relative to 
the other two vignettes. Instead of an architect adjusting his problematization to incorporate the concerns and constituencies of the other actors, the negotiation was marked by a show of force. The SFD representative, it should be noted, supported both positions, albeit indirectly, through her involvement in prior negotiations.

\section{Discussion}

The three vignettes illustrate the contribution of an ANT approach to an analysis of the design process which, in turn, presents client engagement in a new light. More specifically, the concept of problematization highlights the way in which negotiations involve, not only expressions of professional interests or client preferences, but competing accounts of the interests of a variety of other actors (human and non-human). The concept of enrolment draws attention to the uncertainty of the process. Problematizations invite actors to buy into a particular account of their interests and to support particular design decisions, while enrolment underlines the possibility that they may resist. Far from scuppering the design process, resistance generally involves the introduction of new problematizations, associated with new or modified design proposals, involving new or slightly modified networks producing new or modified definitions of the issue, solutions and, thus, effects. Finally, attention to durability underlines the role of material objects and, more specifically, devices in fixing particular outcomes. When it comes to clients, the analysis contributes to current understandings of the multiplicity, heterogeneity and fluidity of client interests. Instead of reducing multiplicity to personal or professional characteristics of individual, ANT illustrates the ways that construction actors (human and non-human) think and speak for others and the transformations that ensue. This dynamic, which the concepts of problematization and enrolment highlight, reveals a much more complex and nuanced mode of both professional and client engagement. The discussion which follows develops each of these points.

\section{Design reconsidered}


Studies of project level dynamics often focus on the difficulties posed by inter-firm, interdisciplinary teams working together in temporary organizations. The assumption, in many studies, is that actors with different disciplinary background necessarily approach problems differently (e.g. Bresnen, 1991). While a number of points in the vignettes above support this claim - the architect in the second vignette was concerned to protect his vision of ground floor open spaces, the acoustician in the third vignette wanted to achieve a technically ambitious goal of $20 \mathrm{NR}$ - they also challenge it or rather nuance the point.

In terms of decision-making, ANT shifts the focus away from discrete actors with fixed interests and identities to an exploration of the processes by which issues and problems come to be specified and solved. The concept of problematization draws attention to the way in which negotiations around design issues are generally framed and defended in the name of other stakeholders, present and absent. Thus, in the case of the building location, the architect and Heads of School appealed to the interests of staff, students, visitors and the campus (in the form of academic integration) to support their different preferences.

Similarly, in vignette 2, the Head of the SFD defended her interest in the height and location of the theatre in the name of future actors, theatre crews and her own aesthetics. Not only did the key actors articulate multiple interests in the course of the discussion, they ascribed different interests to the multiple stakeholders in whose name they purported to speak. Thus visitors were alternately depicted as wanting ease of access and a vibrant local community life, while future students in the SFD figured alternately as actors and crew, with different concerns.

From the perspective of construction research and professionals, this observation both complicates and simplifies the task of project coordination. On the one hand, it challenges the assumption that client or professional interests can be reduced to a single issue or criteria or even world view (Boyd and Schweber, 2014). On the other hand, it highlights the capacity of construction professionals and clients to understand, appreciate and even adopt 
multiple perspectives (or in ANT terms, enrolment) and their importance in the achievement of consensus.

Whereas problematization points to the multiplicity of actors evoked and multiplicity of identities ascribed to them in the course of a negotiation, the concept of enrolment (also) highlights the ability of actors to challenge those depictions and, in doing so, redefine the issue and the design options. This was clearly evidenced in the first vignette when the public effectively reframed the issue of building location to a concern for green space which, in turn, led to the introduction of a third option.

In terms of the design process, another finding to emerge from the ANT analysis concerns a distinct take on the the interdependency of different design features. In the ANT analysis above design decisions are analysed as the outcome of a dynamic network of human and non-human actors. This analytic framework draws attention to the displacement of design issues in the course of a negotiation. Thus, the negotiation around the floor space morphed from a negotiation around the size and height of the theatre into a discussion about the location of the storage room. It also highlights the way in which this interdependency effectively privileges certain interests and sidelines others, potentially without the client realizing it (see below). For example, in the case of floor space the shift in focus from theatre to storage room effectively sidelined concerns for the thermal comfort of the actors. Whereas issues of interdependency are often treated as technical problems, ANT points to the role of the negotiation process, contingency and distributed agency in the production of physical clashes..

A distinctive feature of ANT analyses is the symmetrical approach to human and nonhuman actors. One of the main theoretical points in many ANT studies is a demonstration that non-human actors 'make a difference' to the outcome of negotiations. This paper incorporates this basic ontological model, but moves the theoretical discussion on by exploring variations in the involvement of non-human actors. The analysis builds on the ANT distinction between mediators (non-human actors) and intermediaries - more passive 
objects which communicate specific problematizations, but do not change the content of the message. More specifically the analysis builds on one specific type of intermediary, namely devices, and their role in the stabilization and durability of particular networks and their effects.

The three vignettes offer a number of illustrations of non-human actors and of devices and their contrasting roles in the ongoing negotiation of design decisions. In discussing this issue it is important to note that the difference stems from the function of the object in the network at a given moment in time and not from any intrinsic characteristics. Thus, building plans functioned alternatively as actants and devices at different moments in the ongoing negotiations.

In the first vignette, the plan displayed in the foyer during the public consultation figured in the design process as an actor in its own right. By omitting any reference to either a vibrant campus or easy access and by visually drawing attention to the green space, it actively enrolled the public in its visual account of the problem. Similarly, in the second vignette, the space cards figured as an actor, displacing the focus of the negotiation from the thermal comfort of the actors to the spatially represented issue of the distance between the storage room and Theatres 2 and 3. Finally, in the third vignette, the revised budget limited the options for the floor plan of the roof, thus contributing to the inflexibility of the boiler room and the descending pipes (which threatened the acoustics in the TV studio below). In this example, the budget acted at a (temporal) distance, in the sense that its effect was felt on a prior negotiation in which the design of the boiler room was discussed and eventually fixed.

This ability to act at a distance and to fix networks and associated effects (in this instance the positon of the boiler room) is a key characteristic of devices. Thus, in the second vignette, it was not the architect or the finance person or even the budget which fixed the decision, but rather a myriad of devices which secured the decision of that actor network and protected it in the subsequent discussion about the acoustics in the TV studio. Other examples of 
devices in the vignettes reported above include the comments from members of the public in the comment boxes and the campus plans which were produced early on in the discussion over the building location (all of which were easily modified). In each of these examples, physical objects served to capture and communicate particular problematizations without actively modifying them (at least, not insofar as the available data suggested).

A comparison of the involvement of these different devices points to two quite distinct functions. In the first vignette, devices were produced in the course of negotiations and served to communicate particular problematizations. In the third vignette, they captured and fixed the outcome of prior negotiations, offering an illustration of long-distance control. From a theoretical perspective, one of the contributions of this analysis is its identification of the way in which the overlay of devices contributes to the durability (or inflexibility) of a particular effect in the course of subsequent negotiations. In the third vignette, the ability of the architectural technician to insist on the position of the boiler room and associated pipes can be (at least partly) explained not just by the strength of the floor plan which captured a negotiation that had been previously concluded, but also by the overlay of the plan with the services engineers' area schedule, the architects' plans and the services engineers' drawings. An important finding to emerge from this analysis is the way in which the overlay of devices intensifies their power and, by extension, the durability of the particular decision/design feature.

In reflecting on the contribution of ANT to this analysis, it is helpful to keep in mind the alternative, namely an essentialist association of different actors with professional interests or a systems approach to design which focuses on the physical interdependency of design features, at the expense of the multiplicity of actors and interests, both human and nonhuman, and the processes through which they defined. When it comes to devices such as building plans, a number of construction researchers have explored the role of inscriptions and artefacts such as models and plans in the design process (e.g. Yaneva 2005, Ewenstein and Whyte 2009). The analysis above echoes themes from this work. But, whereas most of 
these focus on knowledge and knowledge production, ANT rejects the treatment of knowledge as independent of the people and the objects that produce it. Instead it draws attention to the variety of different functions which physical inscriptions and artifacts can assume in a building project, ranging from active mediators or non-human actors to more passive intermdiaries. It also underlines their role in the involvement of long distance action and the added strength which the overlay of devices affords to particular networks and associated effects (or, in lay terms, design decisions).

\section{Client engagement re-considered}

These observations both illustrate points in the literature on emergent client needs and open the way for a more dynamic, nuanced conceptualization of client engagement. In keeping with much of the literature cited above, an ANT analysis of design negotiations underlines the ongoing, dynamic character of client preferences, effectively challenging the depiction of clients as uniform, static and external to the design and building process. The analysis of shifting definitions of a problem and associated networks of actors and artefacts also calls into question the search for a single best solution to client preferences and challenges the adequacy of a management approach aimed at the extraction of information (since even individual client preferences are multiple and in flux). Finally, the analysis illustrates the extent to which client needs and preferences emerge in the course of the design process, around detailed decisions.

When it comes to the identity of clients and their preferences, ANT highlights three issues, one of which nuances points in the literature and two of which are more novel. The more common point concerns the multiplicity of client actors and fluidity of individual client preferences in the course of a project. The second and third points involve the impact of materiality on modes of client engagement and the role of devices in limiting or augmenting client power. 
As indicated above, the multiplicity of clients is a common theme in the recent literature on clients and client engagement. The contribution of ANT lies in the insights which it offers into how a broad range of stakeholders are strategically engaged in the minutiae of specific decisions. Thus, whereas most studies focus on clients who are physically present in negotiations, ANT draws attention to the multiplicity of other stakeholders in whose name they purport to speak and the way in which those stakeholder interests are constructed and reconstructed in the course of specific design decisions.

For example, in the first vignette clients from the university spoke up in the interest of their different formal positions, but they also spoke in the name of staff, students and visitors. A key mechanism of persuasion involved the reformulation of various stakeholder interests, often in their absence with little to no evidence of what they 'really' wanted. This is clearly evident in the architects' reformulation of his case for the eastern location by appealing to the interest of 'visitors'. In terms of construction research, this observation points to the need to take into account not only the variety of different client actors, but their broader commitments and the way they are mobilized. It also opens an interesting area of research for scholars of CSR and stakeholder engagement. Whereas those studies usually focus on broad commitments and representations, the analysis above points to the very subtle ways in which stakeholders are evoked in the course of negotiations to support different client preferences.

The second issue concerns variations in the mode of client engagement. More specifically, it highlights variations in the materiality of different negotiations and their consequences. In the first vignette, negotiations were largely between client actors, actors were relatively open to persuasion and devices served primarily to communicate different preferences, rather than to fix decisions. Rough sketches were easily redrawn. Even the written comments in the comment box could easily be ignored and individual pieces of paper, as in the ones which voiced support for the east location, overruled. The vignette thus points to the fluidity 
and multiplicity of client preferences and of material devices at certain moments in the design process.

This situation contrasts with the second vignette where negotiations were largely conducted between two actors, representing the outcome of previous negotiations, with their associated networks and effects. The SFD representative came to the table armed with lengthy conversations with members of the School (of which she was previously the Head) and a clear set of concerns regarding the height of Theatre 1 and the importance of storage space. The architect arrived with a fixed, circumscribed floor plan (with the backing of a previously constituted network involving the finance people - a different client actor), a set of space cards and only a limited number of ways they could all fit into the plan. He also had his own commitment to an open space on the ground floor. In this exchange, the architect controlled the devices (and had the backing of the prior networks which had produced them). The client had multiple constituencies to represent with potentially conflicting concerns and no clear steer (devices).

This latter point draws attention to the way in which individual clients' multiple commitments leaves them open to persuasion and enrolment by 'experts' and in particular experts with devices. At first glance, this observation echoes the large literature on power differences between lay people and experts and the need for knowledgeable clients (Hughes and Hughes, 2013). But the point here is different. One of the contributions of ANT is to draw attention to the processes of persuasion involved in client engagement. The SFD representative's weakness in the second and third vignette were not due to her lack of expertise but, rather, to the heterogeneity and multiplicity of her commitments.

Finally, the third vignette offers an example in which client actors were physically absent from the direct negotiation, but present by proxy. Curiously, the SFD representative figured in both the acoustician's problematization, through the medium of the agreed upon figure of $20 \mathrm{NR}$, and in the architect technician's plan, into which she was previously enrolled. This observation again affirms the variety of different 'interests' which the same client actor 
assumes at different points in a project and the way in which previous decisions can come home to haunt in unanticipated ways. In the absence of client actors, the negotiation came down to the durability of the different devices. The architectural technician's plans were stronger not because paper trumps numbers, but because they were already interlinked with a number of other devices, including the services engineers' area schedule, the architects' plans and the service engineer's drawings

The third, related issue concerns the strength or power of client actors in the different negotiations. The ANT analysis of devices and durability draws attention to the way in which prior negotiations and their incorporation into material devices serves to fix particular details, rendering certain design features non-negotiable. While the role of contract documents in fixing particular commitments is explicit and by design, the third vignette draws attention to the role of a wide variety of less formal devices in securing particular design features.

\section{Conclusion}

In terms of theory, this paper has developed an approach to different and changing client expectations using the ANT concepts of problematization, enrolment and durability. This analytic framework both supports emergent views of client preferences and offers a novel account of their development in the course of a project. Instead of relating client preferences to characteristics of individual clients or to project-wide criteria of time, cost and quality, the analysis explores the production of those preferences in the course of negotiations around specific design processes. The approach also helps to explain how some preferences come to influence outcomes (contribute to network effects) and others are abandoned or ignored.

The findings of this study have a number of practical implications regarding the incorporation of client interests over the course of design projects. First, they point to the need for clients to recognize and render explicit the heterogeneity and multiplicity of both client actors and of the stakeholders they purport to represent. While tensions between 
different considerations and issues cannot be avoided, they can be reflected upon and addressed, rather than falling by the wayside in the messiness of knock-on effects. Second, they draw attention to issues involved in the appointment of formal client representatives. The client representative is often charged with defending the interest of multiple client actors, with multiple interests; this is not a simple task. Third, it suggests that issues and interests are often only formulated and articulated in the course of negotiations around very specific design features. Since many of those issues are unanticipated, they cannot be collected up-front or translated into 'information'. Clients are not mere initiators of projects. Instead, client engagement needs to be conceptualized as a recursive process, with attention to who and what is being excluded as well as included. Finally, the analysis draws attention to the role of inscriptions and material devices in the fixing of clients' interests. Rather than simply capturing client interests, devices have the potential to transform them in unintended ways. In some instances they may be very effective in protecting particular decisions (rendering them durable); in others they may prove to be weak representatives.

Moving beyond the issue of client engagement the perspective sketched herein also puts discussions about fragmentation of construction projects and the need for integration in a new light. Clearly, integration is a rational and useful response to fragmentation. The challenge suggested by this analysis is not more integration. Rather, it is a more explicit and continuous interaction that deals with the constantly-changing landscape of the extended mix of people, organizations and interests that are usually concealed behind the label of 'client'. Construction projects are, by their nature, integrated, not at the level of formal roles, but at the level of the devices which carry decisions taken at one point in time into subsequent ones and by the overlay of inscriptions, material objects and devices which render certain effects durable. In addition to setting up procedures to encourage engineering specialists or contractors to engage earlier in the design process or developing management techniques to gather and communicate information, we would be well-advised to explore how that engagement makes a difference and how that additional layer of devices figures in the heterogeneous, fluid, dynamic networks by which buildings are built. 
Turning to ANT, the discussion makes a number of contributions to ANT in general and to its deployment on construction research more specifically. It also points to new directions for further inquiry. Whereas most ANT studies emphasise the fluidity and multiplicity of everything, the concept of devices and interest in durability offers an analytic vehicle to explore the relative difficulty in making and unmaking particular decisions (without losing the significant contribution of an ANT ontological framework). In terms of construction research, it suggests one way to begin to incorporate an ANT understanding of power and more specifically long distance control into the analysis of project dynamics. It also introduces a novel approach to the role of materiality in project fragmentation/integration. 


\section{References}

Alderman, C. and Ivory, N. (2011) Translation and convergence in projects: an organizational perspective on project success. Project Management Journal, 42(5), 17-30.

Banwell, H (1964) The Placing and Management of Contracts for Building and Civil Engineering Works. London, HMSO.

Bowen, P A, Pearl, R G and Edwards, P J (1999) Client briefing processes and procurement method selection: a South African study. Engineering, Construction and Architectural Management, 6(2), 91-104.

Boyd, D. and Chinyio, E. (2006) Understanding the construction client. Oxford: Blackwell.

Bloor, D. (1976) Knowledge and social imagery. Chicago, University of Chicago Press.

Bresnen, M J (1991) Construction contracting in theory and practice: A case study. Construction Management and Economics, 9, 247-62.

Bresnen, M. J. and Marshall, N. (2000) Building partnerships: case studies of client-contractor collaboration in the UK construction industry. Construction Management and Economics, 18(7), 819-32.

Callon, M. (1986a). The sociology of an actor-network: the case of the electric vehicle. In: M. Callon, J. Law, and A. Rip (Eds.), Mapping the dynamics of science and technology, London, Macmillan Press, 119-134.

Callon, M. (1986b) Some elements of a sociology of translation: domestication of the scallops and the fishermen of St Brieuc Bay. In: Law, J. (Eds.) Power, action and belief: a new sociology of knowledge, London, Routledge \& Kegan Paul, 196-233.

Cherns, A. B. and Bryant, D. T. (1984) Studying the client's role in construction management. Construction Management and Economics, 2, 177-84. 
Chinyio, E., Olomolaiye, P., Kometa, S. and Harris, F. (1998) A needs-based methodology for classifying construction clients and selecting contractors. Construction Management and Economics, 16, 91-98.

Egan, J (1998) Rethinking construction: the report of the Construction Task Force to the Deputy Prime Minister, John Prescott, on the scope for improving the quality and efficiency of UK construction, London: Department of the Environment, Transport and the Regions Construction Task Force.

Engwall, M, (2003) No project is an island: linking projects to history and context; Research Policy, 32(5), 789-808.

Ewenstein, B. and Whyte, J. (2009) Knowledge practices in design: the role of visual representations as epistemic objects. Organization studies, 30(1), 7-30.

Gann, D.M. and Salter, A.J. (2000) Innovation in project-based, service-enhanced firms: the construction of complex products and systems. Research Policy, 29(7/8), 955-972.

Giddens, A. (1984) The constitution of society. University of California Press: Berkeley and Los Angeles.

Harty, C (2005) Innovation in construction: a sociology of technology approach. Building Research E Information, 33(6), 512-22.

Harty, C. (2008) Implementing innovation in construction: contexts, relative boundedness and actor-network theory. Construction Management and Economics, 26, 1029-41.

Hedgren and Stehn (2014) The impact of clients' decision-making on their adoption of industrialized building. Construction Management and Economics. 32, 126-145.

Hughes, W.P. and Hughes, C. (2013) Professionalism and professional institutions in times of change. Building Research E Information, 41(1), 28-38. 
Latham, M (1994) Constructing the team: final report of the government/industry review of procurement and contractual arrangements in the UK construction industry, London: HMSO.

Latour, B (1987) Science in action: How to follow scientists and engineers through society. Milton Keynes: Open University Press.

Latour, B. (1988) The Pasteurization of France. Cambridge MA, Harvard University Press.

Latour, B. (1996) Aramis or the love of technology (C. Porter, Trans.). Cambridge MA, Harvard University Press.

Latour, B. (2005) Reassembling the social: an introduction to actor network theory. Oxford, Oxford University Press.

Law, J (1986) On the methods of long-distance control: vessels, navigation and the Portuguese route to India. In: Law, J (Ed.), Power, action and belief: a new sociology of knowledge. London, Routledge, 234-63.

Law, J. (1992) Notes on the theory of the actor-network: ordering, strategy and heterogeneity. Systems Practice, 5, 379-93.

Law, J., and Callon, M. (1992). The life and death of an aircraft: a network analysis of technical changes. In: W. Bijker and J. Law (Eds.), Shaping technology/ building society: studies in sociotechnical change. Cambridge MA, MIT Press, 21-52.

Leung, M., Ng, S.T. and Cheung, S.(2004) Measuring construction project participant satisfaction. Construction Management and Economics, 22, 319-331.

Lingard, H.C,, Cooke T. and Blismas, N. (2012) Designing for construction workers' occupational health and safety: a case study of socio-material complexity. Construction Management and Economics. 30, 367-382 
Liu, A.M.M. and Walker, A. (1998) Evaluation of project outcomes. Construction Management and Economics, 16, 209-19.

Morris, P.W.G. (1994) The Management of Projects. London, Thomas Telford.

Murray, M. and Langford, D.A. (Eds.) (2003) Construction Reports 1944-98. Oxford: Blackwell Science.

Sage, D., Dainty, A., Tryggestad, K., Justesen, L. and Mouritsen, J. (2014) Building with wildlife: project geographies and cosmopolitics in infrastructure construction. Construction Management and Economics, 32, 773-86.

Shen, Q., Li, H., Chung, J., \& Hui, P. Y. (2004) A framework for identification and representation of client requirements in the briefing process. Construction Management and Economics, 22, 213-221.

Tryggestad, K., Georg, S. and Hernes, T. (2010) Constructing buildings and design ambitions. Construction Management and Economics, 28, 695-705.

Winch, G. (1998). Zephyrs of creative destruction: understanding the management of innovation in construction, Building Research and Information, 26(5), 268-279.

Winch, G. (2012) Managing Construction Projects. $2^{\text {nd }}$ ed. Wiley-Blackwell, London.

Woolgar, S. and Latour, B. (1986) Laboratory Life: the construction of scientific facts. $2^{\text {nd }}$ ed. Princeton NJ, Princeton University Press.

Yaneva, A (2005) Scaling up and down: extraction trials in architectural design. Social Studies of Science, 35(6), 867-94.

Yeung, J.F.Y., Chan, A.P.C., Chan, D.W.M. and Li, L.K. (2007) Development of a partnering performance index (PPI) for construction projects in Hong Kong: a Delphi study. Construction Management and Economics, 25(12), 1219-1237. 